Voss, H., Vogel, A., Wagemans, A.M.A, Francke, A.L, Metsemakers, J.F.M., Courtens, A.M., Veer, A.J.E. What is important for advance care planning in the palliative phase of people with intellectual disabilities? A multiperspective interview study. Journal of applied research in intellectual disabilities (JARED) : 2020, 33(2), p. 160-171

$\begin{array}{lll}\text { Postprint version } & : & 1.0 \\ \text { Journal website } & : & \text { https://onlinelibrary.wiley.com/doi/10.1111/jar.12653 } \\ \text { Pubmed link } & : & \text { https://www.ncbi.nlm.nih.gov/pubmed/31441581 } \\ \text { DOI } & : 10.1111 / \text { jar.12653 }\end{array}$

This is a Nivel certified Post Print, more info at nivel.nl

\title{
What is important for advance care planning in the palliative phase of people with intellectual disabilities? A multiperspectiveinterview study
}

\author{
H. Voss ${ }^{1}$, A. Vogel ${ }^{2}$, A.M.A. Wagemans ${ }^{2,3,4}$, A.L. Francke ${ }^{1,5,6}$, J.F.M. \\ Metsemakers ${ }^{4}$, A.M. Courtens ${ }^{3}$, A.J.E. de Veer ${ }^{1}$
}

1 Netherlands Institute of Health Services Research (NIVEL), Utrecht, The Netherlands

2 Maasveld, Koraal, Maastricht, The Netherlands

3 Expertise Centre for Palliative Care, Maastricht University Medical Centre, Maastricht, The Netherlands

4 Department of Family Medicine, Faculty of Health, Medicine and Life Science, Maastricht University, Maastricht,The Netherlands

5 Amsterdam Public Health Research Institute (APH), VU Medical Centre, Amsterdam, The Netherlands

6 Expertise Centre for Palliative Care Amsterdam, VU Medical Centre, Amsterdam, The Netherlands

\section{Correspondence}

Hille Voss, Netherlands Institute of Health Services Research (NIVEL), Utrecht, The Netherlands.

Email: h.voss@nivel.nl

\section{Funding information}

ZonMw, Grant/Award Number: 844001201

\begin{abstract}
Background: Advance care planning (ACP) is the process of discussing and documentingwishes and preferences for future care. Research about ACP for people withintellectual disabilities (ID) is limited. This study describes what is important for ACPin the palliative phase of people with intellectual disabilities.

Method: In-depth interviews were conducted with people with intellectual disabilities( $\mathrm{n}$ $=5)$, relatives $(n=7)$ and professional caregivers $(n=8)$. Qualitative data wereanalysed inductively, using the principles of thematic analysis.
\end{abstract}


Voss, H., Vogel, A., Wagemans, A.M.A, Francke, A.L, Metsemakers, J.F.M., Courtens, A.M., Veer, A.J.E. What is important for advance care planning in the palliative phase of people with intellectual disabilities? A multiperspective interview study. Journal of applied research in intellectual disabilities (JARED) : 2020, 33(2), p. 160-171

Results: Important themes in ACP were as follows: tailoring care, working as a teamand taking and giving time. The perceived role of people with intellectual disabilitiesin ACP was to express their wishes. Relatives had a signalling, representing and contributing role. Professionals felt their role was to inform, collaborate and coordinate.

Conclusions: A staff training programme about ACP should cover how to build and maintain close relationships, provide a safe environment and address ACP as an integral part of care.

\section{KE Y W O R D S}

advance care planning, decision-making, end of life, intellectual disability, palliative care, staff

\section{Introduction}

People with intellectual disabilities (ID) are an ageing population and, in line with the general population, are living longer due to social and medical advances (Patja, livanainen, Vesala, Oksanen, \& Ruoppila,2000). This is linked to growing prevalence of life-threatening illnesses at an older age, such as progressive cancer, chronic cardiovascular diseases, chronic lung diseases and dementia (Heslop et al., 2014; Janicki, Dalton, Henderson, \& Davidson, 1999). Therefore, more attention is currently being given to how to support older people with intellectual disabilities who are in need of palliative care (Bigby, 2002; McKenzie, Mirfin-Veitch, Conder, \& Brandford, 2017; Tuffrey-Wijne, 2003; Watson, Wilson, \& Hagiliassis, 2017). The World Health Organization defines palliative care as 'an approach that improves the quality of life of patients and their families facing the problem associated with life-threatening illness, through the prevention and relief of suffering by means of early identification and impeccable assessment and treatment of pain and other problems, physical, psychosocial and spiritual' (WHO, 2019).

Despite the growing attention paid to palliative care for people with intellectual disabilities (ID), very little work has been done on the views of people with intellectual disabilities regarding their preferences for end-of-life care (Kirkendall, Linton, \& Farris, 2017; Voss et al., 2017). To increase the quality of palliative care, it is important to identify the end-of-life wishes and preferences of people with intellectual disabilities (Bekkema, de Veer, Hertogh,\& Francke, 2014; Hahn, Fox, \& Janicki, 2015; McKenzie et al., 2017; Watson et al., 2017). The process of discussing and documenting wishes and preferences is referred to as advance care planning (ACP). ACP is a person-centred, ongoing process of communication between the patient, relatives and professionals that facilitates patients' understanding, reflection on and discussion of goals, values and preferences for future care (Rogne, 2013). As ACP is a broad concept, medical decisions should be part of discussions, but ACP also focuses on psychosocial and spiritual matters in the palliative phase. Moreover, ACP takes place not just within the context of the physician-patient relationship but also within relationships with relatives and other professionals who are important for the support and experiences of the person with intellectualdisabilities (Singer et al., 1998; Vrijmoeth, Christians, et al., 2016; Watson et al., 2017).

Research has demonstrated that people with mild-or-moderate intellectual disabilities are often able to express their preferences about end-of-life issues (Bekkema, de Veer, Hertogh, \&Francke, 2016; Chow et al., 2017; McEvoy, Treacy, \& Quigley, 2017; McKenzie et al., 2017; Stancliffe, Wiese, Read, Jeltes, \& Clayton, 2017). Therefore, ACP has the potential to put people with intellectual disabilities more in control of their own care (Kirkendall et al., 2017; McKenzie et al., 2017).

Nevertheless, limited cognitive and communicative capabilities of people with intellectual disabilities mean that professionals experience difficulties in recognizing palliative care needs and initiating 
Voss, H., Vogel, A., Wagemans, A.M.A, Francke, A.L, Metsemakers, J.F.M., Courtens, A.M., Veer, A.J.E. What is important for advance care planning in the palliative phase of people with intellectual disabilities? A multiperspective interview study. Journal of applied research in intellectual disabilities (JARED) : 2020, 33(2), p. 160-171

discussions about future care (Bekkema, Veer, Albers, et al., 2014; Brown, Burns, \& Flynn, 2003; Stein, 2008; Vrijmoeth, Barten, et al., 2016; Vrijmoeth, Christians, et al., 2016; Watson, 2016; Wiese, Dew, Stancliffe, Howarth, \& Balandin, 2013; Wiese, Stancliffe, Dew, Balandin, \& Howarth, 2014). Moreover, the presence of co-morbid medical conditions in this population and complex social circumstances adds complexity to the ACP process (van Schrojenstein Lantman-De Valk, Metsemakers, Haveman, \& Crebolder, 2000; Wagemans, van Schrojenstein Lantman-de-Valk, Tuffrey-Wijne, Widdershoven, \& Curfs, 2010). The challenges of communicating and interpreting the future care needs of people with intellectual disabilities mean that care is not always adjusted proactively; rather, adjustments tend to be made in response to problems that have arisen (Heslop et al., 2014; McKenzie et al., 2017). Therefore, people with intellectual disabilities are at risk of having their wishes overlooked or misunderstood at the end of life (Tuffrey-Wijne \& McLaughlin, 2015; Watson et al., 2017).

If palliative care is to be in line with what individuals with intellectual disabilities want and need, it is important to study what is needed to implement ACP in the palliative phase. Previous research has given useful information on how to provide tailored palliative care for people with intellectual disabilities (Hahn \& Cadogan, 2011). Moreover, incorporating the views of people with intellectual disabilities themselves about end-of-life care is critical to working out how best to support them (Savage, Moro, Boyden, Brown, \& Kavanaugh, 2015). However, to our knowledge, there has not yet been an empirical exploration of what is important for ACP from multiple perspectives, namely the perspectives of people with intellectual disabilities themselves and their relatives and professionals. Therefore, two main research questions were addressed in this multi-perspective interview study: (a) 'What should ACP look like?' and (b) 'What roles should people with intellectual disabilities, relatives and professionals have in ACP?' The results of this study will be used for the development of a staff training programme about ACP for people with intellectual disabilities.

\section{$2 \quad$ Method}

\subsection{Design}

A qualitative design was used, involving individual in-depth interviews with a total of eight professionals, seven relatives and fivepeople with moderate intellectual disabilities.

\subsection{Ethical consideration}

The protocol and topic list for the interviews were approved by theMedical Ethical Committee of the VU University Medical Centre.Study participation was voluntary. The responses were anonymousand non-traceable to individuals.

\subsection{Partcipants}

Professionals $(n=8)$ and relatives $(n=7)$ who were close to a person with intellectual disabilities in the palliative phase or to an individual with intellectual disabilities who had recently died after a period of illness were identified by physicians who were employed at five intellectual disability residential care organizations in the Netherlands. Via the physicians who functioned as recruiters in our study, potential participants received a letter from the relevant intellectual disability care organization informing them about the aim and content of the study and asking them to sign an informed consent form if they wished to participate. Other than having prior experience with caring for a person with intellectual disabilities at the end of life, there were no inclusion criteria for the professionals or relatives. 
Voss, H., Vogel, A., Wagemans, A.M.A, Francke, A.L, Metsemakers, J.F.M., Courtens, A.M., Veer, A.J.E. What is important for advance care planning in the palliative phase of people with intellectual disabilities? A multiperspective interview study. Journal of applied research in intellectual disabilities (JARED) : 2020, 33(2), p. 160-171

People with intellectual disabilities $(n=5)$ were recruited from one of the intellectual disability residential care organizations by their intellectual disability physician in consultation with care staff. Potential participants with intellectual disabilities were informed about the subject of the interview, and information was provided verbally; they could then verbally provide informed consent. The information was provided by their care staff, who also emphasized that participation was voluntary. The inclusion criteria for people with intellectual disabilities were as follows: (a) having an understanding of the concept of death and dying; (b) having previous experience with being seriously ill and/or being hospitalized themselves; and (c) being at least 18 years old. We asked care staff to assess these criteria in their clients. The exclusion criterion was (for ethical reasons) having a lifelimiting illness or receiving palliative care themselves. However, most participants had a vulnerable health situation due to their age (three of the five participants were over 80 years old). Table 1 shows the background characteristics of the participants.

\subsection{Data collection}

A topic list was used to guide the interviews (see Box ). The topic list was developed together with all the co-authors, who are researchers and practitioners working in the field of either family medicine or palliative care. Open questions were used, encouraging interviewees to describe personal wishes for and views about ACP in their own words. For participants with intellectual disabilities, the number and sort of questions were adjusted to suit their cognitive and communicative abilities. In interviews with people with intellectual disabilities, the subject of the interview was introduced with a short picture story about a woman with intellectual disabilities who heard from her doctor that she was incurably ill. In two interviews with people with intellectual disabilities, the introduction story was skipped because the participants had been prepared for the interview by care staff and shared their ideas about ACP as soon as the interviewer arrived. Interviews were held at a place preferred by the interviewees and were conducted by the first and/or second author (HV and AV). All participants with intellectual disabilities were familiar with the second author, who is involved in their care as a specialized intellectual disability physician. Aftercare was discussed with participants' care staff to ensure that support was available if needed. The interviews with professionals and relatives lasted 1 hour. The interviews with people with intellectual disabilities lasted approximately 15-30 minutes. The interviews were audio- or video-taped and transcribed verbatim.

Data collection and analysis took the form of a cyclical process of data collection-analysis-more data collection. The number of interviews in this study was not pre-determined but was chosen on the basis of the principle of data saturation (Guest, Bunce, \& Johnson, 2006). After fifteen interviews, no new information or themes were observed and data saturation was reached.

\section{[Table 1]}

\subsection{Data analysis}

The data were analysed inductively, using principles of thematic analysis (Braun \& Clarke, 2006). Thematic analysis can be considered a pragmatic, realist qualitative method, aimed at reporting experiences, meanings and the reality of participants. The analysis process is stepwise. It starts with noticing and looking for issues of potential interest in the data, which begins during data collection.

As a first step, interviews were reread, important text fragments regarding the research questions were noted, and ideas were marked for coding by two authors (HV and AdV). A qualitative softwareanalysis programme was used to facilitate the coding process (MAXQDA, 2017). Descriptive codes were used, based directly on words or sentences that the interviewees used (e.g. 'Stronger than I am able to be'), as well as interpretative codes (e.g. 'Deciding together'). Interview fragments 
Voss, H., Vogel, A., Wagemans, A.M.A, Francke, A.L, Metsemakers, J.F.M., Courtens, A.M., Veer, A.J.E. What is important for advance care planning in the palliative phase of people with intellectual disabilities? A multiperspective interview study. Journal of applied research in intellectual disabilities (JARED) : 2020, 33(2), p. 160-171

with the same codes were continuously compared and discussed by HV and AdV. In the next step, codes were sorted into potential themes. Potential main themes and corresponding subthemes were then formulated. Themes and subthemes were also discussed with the other co-authors (AV, AW, AC, $\mathrm{JM}$ and $\mathrm{AF}$ ), who individually reviewed the themes and subthemes by reading and analysing at least one interview. After slight adjustments in formulations of themes and subthemes and their interpretations, consensus was reached with all authors about the themes. In the next step, the themes were reviewed in relation to the entire data set and refined in a discussion. Subsequently, the researchers further identified the essence of the themes and determined what each theme was about and what aspect of the data it captures. As a next step, definitive themes and subthemes were formulated in consultation with all authors. Finally, all co-authors as well as peer researchers reflected on the draft paper and the main themes presented (the 'peer debriefing'). In the draft and final papers, pseudonyms were given to participants to maintain anonymity.

\section{Results}

Thematic analysis of the interviews $(n=15)$ resulted in the identification of three themes and six subthemes, addressing research question (a) 'What should the ACP process look like?' (see Figure 1).

\section{[Box 1]}

A description of the roles is depicted for research question (b) 'What roles should people with intellectual disabilities, their relatives and professionals have in ACP?' (see Figure 2). The results are described in detail below.

\subsection{What should the ACP process like}

\subsubsection{Tailoring care}

Advance care planning is perceived as a tailor-made process. Each individual is different and has various care needs that needed to be taken into account. According to the participants, there is no single right way to provide ACP. Two subthemes emerged in relation to what is needed to provide tailored care.

\section{Standing close}

Good knowledge of the person with intellectual disabilities was felt to be necessary in order to shape the ACP process to suit the individual with intellectual disabilities and their relatives. For example, to involve the person with intellectual disabilities in the ACP process appropriately, information is needed about that person's life history and previous experiences with illness and losses.

\section{[Figure 1]}

\section{[Figure 2]}

Participants emphasized the importance of close relationships with everyone directly involved in the care for the person with intellectual disabilities, in which open communication can take place.

One parent clarified:

No, but they just know him. ...He is also placed in care with a fixed group. He is lucky with that, because these people have all known each other for like 30 years. 
Voss, H., Vogel, A., Wagemans, A.M.A, Francke, A.L, Metsemakers, J.F.M., Courtens, A.M., Veer, A.J.E. What is important for advance care planning in the palliative phase of people with intellectual disabilities? A multiperspective interview study. Journal of applied research in intellectual disabilities (JARED) : 2020, 33(2), p. 160-171

And well, yes, that is a very good team. Yes, they just do that [communicate] very well, with only half a word you know, you know what it is. Yes, they are, it is a very good place for him. - Interview 6 , relative

One of the participants with intellectual disabilities also spoke about the need for familiar people caring for and about her:

Because a stranger... I can't handle people I don't know. Like here, these care professionals, and this girl who works with us now, she is a student. I need to see who it is. Because I really can't deal with them otherwise.

I immediately get in a conflict [with them]. - Interview 3, participant with intellectual disabilities

\section{Connecting with the person with intellectual disabilities}

To be able to truly simulate what the person with intellectual disabilities wishes, it is import to set aside own preferences and to model what that person stands for in their life, and adjust care according to their goals and needs. One professional elucidated the need to connect to the individual in order to be able to reflect the wishes of the person with intellectual disabilities:

It is of course essential to act and think in the interest of the client [person with ID]... that should be a requirement. ... It is important to know who you are talking about, [especially] if people cannot talk about it any more [themselves]. In what other way could you make a decision? Then the basis on which you make decisions would be very medical or mechanically.-Interview 14 , professional

Additionally, professionals found it important to adapt the ACP process to suit the level of understanding and experiences of the person with intellectual disabilities. One professional explained how she responded to fears from an individual with intellectual disabilities about what happens after death:

For example, there was a client [with ID] who wanted to take her television with her when going to heaven, [that was] very important [for her]. Or her electric wheelchair needed to go with her because how else could she move there?... It was very important for her; 'what is heaven like?'. You [As a professional] have to deal with that very seriously, like; 'Yes, of course it can come to heaven with you', or; 'No that is not possible, but perhaps they have a very large cinema [in heaven]. Or they have televisions and you do not have to bring your own.' So these things are important for clients. - Interview 12, professional

\subsubsection{Working as a team}

The ACP process requires teamwork. Participants described various people involved in the care for the person with intellectual disabilities as participating in ACP discussions and decisions. Two subthemes were identified. 
Voss, H., Vogel, A., Wagemans, A.M.A, Francke, A.L, Metsemakers, J.F.M., Courtens, A.M., Veer, A.J.E. What is important for advance care planning in the palliative phase of people with intellectual disabilities? A multiperspective interview study. Journal of applied research in intellectual disabilities (JARED) : 2020, 33(2), p. 160-171

\section{Deciding together}

According to participants, it is important that everyone who is involved in the care for persons with intellectual disabilities who need palliative care should work together to inform one another and identify whether things are going well or not. Participants with intellectual disabilities said that their relatives should be informed about their health situation, because.

'Then they [relatives] know what is wrong with me' - Interview 2, participant with intellectual disabilities (2), and 'Otherwise they [relatives] would worry' - Interview 5 , participant with intellectual disabilities

In decision making about future care, different beliefs played a role. The participants felt it was important to discuss with everyone who is involved how best to act in the interests of an individual with intellectual disabilities. In this way, decisions can be made that improve the quality of life, and care can be adjusted to changing needs. Moreover, for relatives as well as for professionals, there is a need for consensus on the decisions for future care. One parent clarified why he felt it was important to have care staff involved in discussions about the future care for his son with intellectual disabilities:

But in all these [ACP] discussions, there is also just, his direct caregivers are there. We wouldn't want it without them being there, because, yes, they are there every day, they just need to deal with it. And they [daily care professionals] also needed to know what we [parents] thought. - Interview 6, relative

\section{Trusting each other}

All participants indicated that trust was essential in discussing insecurities and fears, and in making decisions for future care. Relatives explained that it is important to be able to rely on the expertise of professionals in providing and adjusting care according to the needs of the individual. A sister explained:

.. if a decision needed to be taken, they would let me know and asked if it was fine. Well yes, I thought they[professionals] will know best how to arrange it. ... We[as a family] just knew, they are caring for $\mathrm{T}$. and for the other residents every day. So they will know better than us what to do.-Interview 7, relative

Professionals explained that honesty and openness within a team of people caring for and about a person with intellectual disabilities contributed to a more positive and calmer ACP process.

Moreover, the professional and personal experience of professionals with palliative care and losses plays a role in their ability to openly discuss ACP. One professional said that it takes time to feel comfortable taking care of people who need palliative care. Her experience is that it is helpful to be honest about this, to be able to share this with the team and to feel free to ask for help if needed:

I notice with us, also within the team, it is very discussable. We don't avoid that subject at all and that is pleasant, because I have worked in a team where it was harder. That was with children and then you sometimes have colleagues who can't deal with that for themselves... they really have something like: 'I don't want to provide end-of-life care and I think that's scary'. Here as well, I also have colleagues 
Voss, H., Vogel, A., Wagemans, A.M.A, Francke, A.L, Metsemakers, J.F.M., Courtens, A.M., Veer, A.J.E. What is important for advance care planning in the palliative phase of people with intellectual disabilities? A multiperspective interview study. Journal of applied research in intellectual disabilities (JARED) : 2020, 33(2), p. 160-171

here who are younger, who have not yet had clients who have died. The first time is very difficult, [not just as a professional,] but also as a person. Here [in our current team], I notice that it is discussable. - Interview 15, professional

\subsection{3 | Taking and giving time}

Advance care planning is characterized by the participants as a dynamic, continuous process with ongoing discussions. Proactive care and making decisions about future care required time and attention. Two important subthemes are as follows: (a) preparing and thinking ahead and (b) making room for emotions.

\section{Preparing and thinking ahead}

Professionals said that in some cases the ACP process had a noticeable beginning, for example because of a diagnosis of a life-limiting illness, when it is clear for everyone involved that wishes and treatment options for future care need to be discussed. However, for most people with intellectual disabilities, ACP was experienced as a slow process, in which time is needed and should be used to adjust to the changing situation and decisions should be made step by step, with ongoing adjustment for the current situation. A professional described her experience with adjusting ACP decisions in the palliative phase:

Yes, and decisions can also be reversed because we had that once with a client [person with ID], that a decision [to not force her to drink] was made because she was asphyxiating more and more, with every drop [she drank], she asphyxiated. And that was really when we thought the end had come and then she, actually after more than a week, she started drinking again. Then we changed that again too, because you could notice that she had the need to, she wanted that again. It is a process: adjusting, tuning, resetting and then thinking ahead again.Interview 12, professional

Some participating professionals and relatives described that they experienced talking with or about someone with intellectual disabilities at the end of life to be difficult for them as well as for the individual with intellectual disabilities. One participant with intellectual disabilities (interview 1) answered 'I would be shocked' in relation to the question what he would do if the doctor disclosed unfavourable information about his health. All participants with intellectual disabilities knew that if they had a disease that could not be cured, they would die. However, professionals indicated that people with intellectual disabilities often found it scary to think about the consequences of their situation. In response to 'dying', one participant with intellectual disabilities said:

I do not think about that yet. That will take a long time.-Interview 2, participant with intellectual disabilities

Acceptance of decline was described by professionals as a process that requires time. It was therefore felt to be important that professionals proactively inform everyone who is involved about the current situation and are realistic when discussing ACP, for example, about treatment options for future care. In this way, the person with intellectual disabilities and their relatives could be better prepared and have a better understanding of what can be expected in the future. ACP was also found to be helpful for professionals so that they know how to best support an individual in changing 
Voss, H., Vogel, A., Wagemans, A.M.A, Francke, A.L, Metsemakers, J.F.M., Courtens, A.M., Veer, A.J.E. What is important for advance care planning in the palliative phase of people with intellectual disabilities? A multiperspective interview study. Journal of applied research in intellectual disabilities (JARED) : 2020, 33(2), p. 160-171

situations. A professional explained that it might be hard to start discussions in advance, but it helps to ensure peace in the final phase of life, which is important for a good farewell:

It is just hard when it [the need for ACP] is spoken out loud. And if you can substantiate it very well, then the family understands. Then they see, then they say, 'actually yes, you are telling now what I actually already have seen'. And then you also see that the family is very happy with that afterwards. That everything is just addressed in a timely manner. That not everything needs to be arranged at the last minute, that a lot of things are just fixed, that they really calmly, can be present in the phase of dying. Without having all stuff on your mind like: 'this needs to be done, that needs to be done'. That is not necessary anymore.- Interview 12 , professional

\section{Making room for emotions}

Having discussions about future care for a person with intellectual disabilities and making decisions for or together with that person can have a big impact and can be accompanied by strong emotions according to participants. Therefore, relatives and professionals recommended taking the impact that ACP in the palliative phase can have into consideration. In relation to personal experiences with discussions about future care for her son with intellectual disabilities, one mother notes the importance of approaching ACP gently and sensitively, with attention to personal and emotional support if needed:

'... But always pay attention to the feelings. You can bring it up very technically, but don't just keep it there. Also ask what they think is important for their child [with ID]. And don't just say: 'I decide'.' She also talked about the difficulty she experienced signing a do not- resuscitate order for her son with intellectual disabilities, knowing that such decisions can have far-reaching consequences:

....as if you are Lord and God over someone's life. Something like that. You have to know with every fibre [of your being] that you do it for them, that you do something for him, that I do something for him what I [would] do for myself also [in the same situation]. That is, that was very important to me, to get that feeling very clear. So it took a while, before I put my signature [on the do-not-resuscitate order]... I could talk considerably to the doctor about it when she called, like 'Did you already send that back? Because I have nothing yet.' Then we also talked about it. I mean, she also had the time for that. In the end it remains my signature, but it is nice if you have someone on the other side who also has time to talk about something like this. - Interview 10 , relative

One social worker (interview 15) explained ACP should be considered as a 'human approach' rather than a more technical or procedural approach. Moreover, one intellectual disability physician described that there should be room to open up about feelings that arise, including as a professional:

I think it would beneficial to also name your own feelings, you are allowed to have feelings too [as a professional]. It might be better if you name them [your own feelings]. Without any consequences, but just that it, well it is also difficult for you as a physician. Maybe I have been too distant in the past too ... Yes, so when I look 
Voss, H., Vogel, A., Wagemans, A.M.A, Francke, A.L, Metsemakers, J.F.M., Courtens, A.M., Veer, A.J.E. What is important for advance care planning in the palliative phase of people with intellectual disabilities? A multiperspective interview study. Journal of applied research in intellectual disabilities (JARED) : 2020, 33(2), p. 160-171

back then I think it is important to be able to talk about emotions. - Interview 11, professional

\subsection{What roles should people with intellectual disabilities, their relatives and} professionals have in ACP?

Roles of people with intellectual disabilities in ACP.

The interviews also addressed the roles of the individuals with intellectual disabilities in their own ACP process. Participants with intellectual disabilities wanted to be informed about their health situation because, as one participant explained simply:

If I know what's wrong with me, then I can do something about it.-Interview 5, participant with intellectual disabilities

According to the participants, people with intellectual disabilities have an expressive role in ACP. Based on their own previous experiences and wishes, people with intellectual disabilities can communicate their preference, sometimes verbally but more often in non-conventional ways. When asked by the interviewer why she wanted to be involved in ACP, one participant with intellectual disabilities replied:

It is my life! - Interview 4, participant with intellectual disabilities

However, people with intellectual disabilities often find direct participation in decisions about future care difficult. One participant with intellectual disabilities $(P)$ told the interviewer $(I)$ that she wanted the people close to her to make decisions regarding future care on her behalf:

$\mathrm{I}$ : And if decisions need to be taken?

P: They [doctor, staff, relatives] need to do that too.

I: Why all those people together?

$\mathrm{P}$ : They are stronger than I am able to be.

I: Do you think it's hard [to make decisions]?

P: Yes.-Interview 3, participant with intellectual disabilities (3).

\subsection{1 | Roles of relatives in ACP}

According to professionals, in cases where relatives have a lifelong, close relationship with the person with intellectual disabilities, the relatives can have an important role in interpreting the person with intellectual disability expressions. Therefore, relatives may have a signalling role, since they can recognize dissimilar behaviour. Also, relatives often want to and should have a contributing role in ACP discussions about future care and decision making, depending on their own involvement and desire to be involved in the care for the individual with intellectual disabilities, as a professional explained:

Well, it also depends in what way relatives themselves fulfil that role. Then of course, that is an interaction. Sometimes relatives are very closely involved, they want something very strongly. Then, yes, I explicitly take that into account. There 
Voss, H., Vogel, A., Wagemans, A.M.A, Francke, A.L, Metsemakers, J.F.M., Courtens, A.M., Veer, A.J.E. What is important for advance care planning in the palliative phase of people with intellectual disabilities? A multiperspective interview study. Journal of applied research in intellectual disabilities (JARED) : 2020, 33(2), p. 160-171

are still also relatives, not that much now anymore, but they say: 'you decide, what you decide is fine'. And yes, many people are also in between, they want to think together, but also realize that their scope is limited. - Interview 11, professional

Moreover, relatives have a representing role, as they can participate in ACP as a representative of the person with intellectual disabilities and articulate wishes on their behalf if the individual is not able to do so themselves. In the interviews, relatives expressed their wish to have a say in how best to act in the interest of a person with intellectual disabilities. One parent explained his personal involvement and sense of responsibility about his son with intellectual disabilities:

That is always nice for us like, 'well, he feels good'. And we are doing well as parents; we arranged it [care] well for him. - Interview 9, relative

(6)

\subsubsection{Roles of professionals in ACP}

According to relatives and people with intellectual disabilities, professionals should first of all have an informing role. Professionals should clearly and realistically explain possible future scenarios for care and the treatment options to relatives and/or the person with intellectual disabilities, taking the latter's level of cognitive functioning into account. One participant with intellectual disabilities responded to the question of why it was important to receive information about his health from professionals:

If I know what's wrong with me, perhaps I can do something about it.-interview 5, participant with intellectual disabilities

A parent said in reply to the same question:

Yes, because we wanted to know how his disease would progress and that he wouldn't... wouldn't suffer a lot.-interview 6 , relative

(6).

Secondly, professionals should have a collaborating role. Since ACP requires teamwork, professionals should maintain harmonious relationships and provide a safe environment where all involved are able to openly discuss wishes and options for future care. In the interviews, professionals explained that it is important to take the initiative to discuss wishes and options for future care with relatives and/or the person with intellectual disabilities. One parent described how professionals should start ACP discussions gently:

It is very important to keep discussing the situation continuously. But you [as a professional] should also get a sense of the parents [of people with ID]. Some are really not ready yet to think about the future and death. But you can bring it up very openly. And then parents can always say 'no'. - Interview 10 , relative 
Voss, H., Vogel, A., Wagemans, A.M.A, Francke, A.L, Metsemakers, J.F.M., Courtens, A.M., Veer, A.J.E. What is important for advance care planning in the palliative phase of people with intellectual disabilities? A multiperspective interview study. Journal of applied research in intellectual disabilities (JARED) : 2020, 33(2), p. 160-171

Lastly, professionals should have a coordinating role as they explained that they monitor the changing behaviour of the person with intellectual disabilities; in the end, they are and feel responsible for providing care in line with what the person with intellectual disabilities wants and needs. Professionals should therefore explore and collate the views and wishes of everybody who is involved in the care for a person with intellectual disabilities, as one behavioural specialist explained:

Well, what do we see? Then it's really our role. What do we see as the quality of life? What do we feel is important to a client in their life? You can make a good guess. Yes, some people find it so difficult to give up any of that being in control and independence, right? So you expect that when it gets to them having a feeding tube, for example, they would definitely not be happy about that. You know. And we look at it together like that, you know, what kind of person do we think the client is? Definitely if the level is really low. And what are the thought processes for getting it right here? We really try to do that together, as a multidisciplinary group, preferably actually with relatives or the representative.-interview 14, professional

\section{Discussion}

This study shows that tailoring care, working together and taking and giving time are important themes in the ACP process. To be able to provide ACP in the palliative phase accordance with the wishes and needs of the individual, it is essential to have close and harmonious relationships between individuals with intellectual disabilities, their relatives and professionals. This may be especially important in the palliative phase, where the proximity of death often leads to increasing dependency of the person with intellectual disabilities and requires an intensified caring relationship between the individual with intellectual disabilities, their relatives and professionals (Bekkema, de Veer, Hertogh, \& Francke, 2015). Earlier research also showed that if relational closeness is enhanced, responsiveness is likely to be increased (Watson et al. 2017). Moreover, evidence from studies of surrogate or supported decision making suggest that the ability to 'simulate' another person's wishes is linked to the ability to empathize with that person (Bigby, Whiteside, \& Douglas, 2017; Tunney \& Ziegler, 2015).

In addition, this study showed that ACP in the palliative phase requires significant teamwork, and teamwork is essential in establishing honest, realistic and open communication about possibilities for future care and in making decisions together. Trust was mentioned by the participants in this study as a key factor in being able to work together constructively. This finding is consistent with previous research on palliative care stating that 'good working relationships' and 'openness to cooperation and sharing' were important when aiming for the shared goal of providing the best possible warm, comforting care for the person with intellectual disabilities in the palliative phase (Bekkema et al., 2015; Tuffrey-Wijne, Bernal, \& Hollins, 2010; Wagemans et al., 2012). Open, continuous communication between the individual with intellectual disabilities, their relatives and professionals should be a hallmark of ACP programmes.

Participants with moderate intellectual disabilities highlighted their wish to be informed about their health situation and to have familiar people supporting them in their decision making. However, some participating professionals and relatives said that they found talking with or about someone with intellectual disabilities at the end of life to be difficult for them as well as for the individual with intellectual disabilities. This fear could be a barrier for ACP if it leads to the postponement or avoidance of discussions about needs for future care and the impending death 
Voss, H., Vogel, A., Wagemans, A.M.A, Francke, A.L, Metsemakers, J.F.M., Courtens, A.M., Veer, A.J.E. What is important for advance care planning in the palliative phase of people with intellectual disabilities? A multiperspective interview study. Journal of applied research in intellectual disabilities (JARED) : 2020, 33(2), p. 160-171

(Bekkema, Veer, Albers, et al., 2014; Stancliffe, Wiese, Read, Jeltes, \& Clayton, 2016; Tuffrey-Wijne \& McEnhill, 2008; Wiese et al., 2014). A model for breaking bad news to people with intellectual disabilities was developed in previous research; it describes how people with intellectual disabilities process and understand unfavourable information, and how professionals can use this when they are faced with bad news situations (Tuffrey-Wijne, 2013). Moreover, training must be developed in partnership with staff as that increases the likelihood that it will continue to be used in the long term (Hahn \& Cadogan, 2011; McLaughlin, Barr, Mcllfatrick, \& McConkey, 2014).

The present study also explored the various roles of people with intellectual disabilities, their relatives and professionals in ACP. Participants with intellectual disabilities were considered to have and expressive role, as they communicate their wishes and preferences in their own way, often represented by their relatives. Relatives explained they have an important signalling role in interpreting the person with intellectual disability expressions and contributed to decision making for future care. Professionals saw their role as coordinating ACP, and as in the end, they are responsible for providing care in line with what the person with intellectual disabilities wants and needs.

According to the participating professionals, experience is required to become comfortable and confident in leading ACP discussions. Therefore, it is recommended that professionals receive training in providing ACP as an integral part of care, and in how to do so in a timely manner. Professionals should take the initiative to start discussions about ACP, which should preferably be held before acute decisions need to be made in the last phase of life. This is in line with an earlier study about ACP for people with intellectual disabilities that recommended starting discussions about future care 'as early as possible' and also suggested investigating the ACP process while people with intellectual disabilities are still feeling well (McKenzie et al., 2017).

Although the themes concerning ACP in the palliative phase that were found in this study may also be relevant for other patient groups or care settings, several aspects appear particularly important for people with intellectual disabilities and their relatives. Firstly, people with intellectual disabilities have lifelong disabilities and are often dependent on others throughout their lives. Various specialized professionals have an extensive caring relationship with the individual with intellectual disabilities and their relatives, and professionals are often involved in their care for years or even decades, which is unique in the healthcare sector. Conversely, the close involvement of numerous professionals and relatives can make ACP in the palliative phase challenging, especially in the case of conflicting beliefs and interests (Bekkema et al., 2015; Tuffrey-Wijne \& McLaughlin, 2015). Secondly, people with intellectual disabilities are not always able to clearly communicate their needs or understand the consequences of their situation. Professionals and relatives frequently need to make medical and other decisions on behalf of the person with intellectual disabilities but rely on interpretations of their signals and expressions, which can be a heavy responsibility (Wagemans et al., 2012, 2013; Watson et al., 2017). Thirdly, ACP in the palliative phase may be complex since people with intellectual disabilities often have co-morbidities and are more vulnerable concerning their health (Heslop et al., 2014). Among them, there is a group of people with intellectual disabilities who need palliative care from birth on (Keele et al., 2016). Therefore, it is even more important to talk about the future at an early stage.

\subsection{Strengths and limitations}

The inclusion of multiple perspectives, including first-person information provided by people with intellectual disabilities, is a strength of this study, capturing a range of thoughts and opinions about the important aspects of ACP. The views of people with intellectual disabilities were generally in agreement with the views of relatives and professionals, which further attests to the validity of the findings. 
Voss, H., Vogel, A., Wagemans, A.M.A, Francke, A.L, Metsemakers, J.F.M., Courtens, A.M., Veer, A.J.E. What is important for advance care planning in the palliative phase of people with intellectual disabilities? A multiperspective interview study. Journal of applied research in intellectual disabilities (JARED) : 2020, 33(2), p. 160-171

One limitation that should be noted is that the study participants $(n=20)$ were recruited via intellectual disability care organizations. As a result, the findings may not apply to individuals with milder disabilities who receive care outside the intellectual disability care sector. Moreover, all the participants with moderate intellectual disabilities lived in one residential care organization and were familiar with the second author, who is involved in their care as a specialized intellectual disability physician. This could possibly lead to a selection bias. However, having a familiar professional conducting the interview or being in the same room helped to provide a safe environment for the participants with intellectual disabilities.

Future research could focus on the extent to which the important aspects of ACP found in this study match the views and roles of people with milder intellectual disabilities who live independently and/or receive non-specialized care. While their ACP process might look different, the need for the support and involvement of professionals as well as relatives will conceivably lead to comparable challenges.

\section{CONCLUSION}

People with intellectual disabilities often have numerous professionals and relatives involved in their care, limited cognitive and communicative capabilities and high levels of co-morbidity, which presents challenges for the provision of ACP. Important ACP themes in the palliative phase for people with intellectual disabilities found in this study concern tailoring care to adjust the ACP process to the needs and wishes of the individual, working together as a team so that open communication can take place, and taking and giving time to prepare for future scenarios. Hence, based on these findings, an ACP training programme might cover such aspects as building and maintaining close relationships, providing a safe environment and addressing ACP as an integral part of care. People with intellectual disabilities must have an explicit role in ACP by expressing their wishes, which makes it important for all people involved in their care to learn how best to respond to these expressions. Professionals have a coordinating role in this process, which requires experience and training. Therefore, it is recommended that professionals receive training in how to provide ACP as an integral, continuous process in the care for people with intellectual disabilities

O RCI D

Hille Voss https://orcid.org/0000-0003-3940-6836

\section{References}

Bekkema, N., de Veer, A. J., Albers, G., Hertogh, C. M., Onwuteaka-Philipsen, B. D., \& Francke, A. L. (2014). Training needs of nurses and social workers in the end-of-life care for people with intellectual disabilities: A national survey. Nurse Education Today, 34(4), 494-500. https ://doi.org/10.1016/j.nedt.2013.07.018

Bekkema, N., de Veer, A. J., Hertogh, C. M., \& Francke, A. L. (2014). Respecting autonomy in the end-of-life care of people with intellectual disabilities: A qualitative multiple-case study. Journal of Intellectual Disability Research, 58(4), 368-380. https ://doi. org/10.1111/jir.12023

Bekkema, N., de Veer, A. J., Hertogh, C. M., \& Francke, A. L. (2015). 'From activating towards caring': Shifts in care approaches at the end of life of people with intellectual disabilities; a qualitative study of the perspectives of relatives, care-staff and physicians. BMC Palliative Care, 14, 33. https

://doi.org/10.1186/s12904-015-0030-2 
Voss, H., Vogel, A., Wagemans, A.M.A, Francke, A.L, Metsemakers, J.F.M., Courtens, A.M., Veer, A.J.E. What is important for advance care planning in the palliative phase of people with intellectual disabilities? A multiperspective interview study. Journal of applied research in intellectual disabilities (JARED) : 2020, 33(2), p. 160-171

Bekkema, N., de Veer, A. J., Hertogh, C. M., \& Francke, A. L. (2016). Perspectives of people with mild intellectual disabilities on care relationships at the end of life: A group interview study. Palliative Medicine, 30(7), 625633. https ://doi.org/10.1177/02692 16316640421

Bigby, C. (2002). Ageing people with a lifelong disability: Challenges for the aged care and disability sectors. Journal of Intellectual and Developmental Disability, 27(4), 231-241. https ://doi. org/10.1080/13668 25021 000029294

Bigby, C., Whiteside, M., \& Douglas, J. (2017). Providing support for decision making to adults with intellectual disability: Perspectives of family members and workers in disability support services. Journal of Intellectual and Developmental Disability, 1-14. https ://doi. org/10.3109/13668 250.2017.1378873

Braun, V., \& Clarke, V. (2006). Using thematic analysis in psychology. Qualitative Research in Psychology, 3(2), 77-101. https ://doi. org/10.1191/14780 88706 qp063oa

Brown, H., Burns, S., \& Flynn, M. (2003). 'Please don't let it happen on my shift!' supporting staff who are caring for people with learning disabilities who are dying. Tizard Learning Disability Review, 8(2), 32-41. https ://doi.org/10.1108/13595 474200300016

Chow, A. Y. M., McEvoy, J., Chan, I. K. N., Borschel, M., Yuen, J. H. L., \& Lo, J. Y. M. (2017). Do men and women with intellectual disabilities understand death? Journal of Intellectual Disability Research, 61(12), 11301139. https ://doi.org/10.1111/jir.12431

Guest, G., Bunce, A., \& Johnson, L. (2006). How many interviews are enough? An experiment with data saturation and variability. Field Methods, 18(1), 59-82. https ://doi.org/10.1177/15258 22X05 279903

Hahn, J. E., \& Cadogan, M. (2011). Development and evaluation of a staff training program on palliative care for persons with intellectual and developmental disabilities. Journal of Policy and Practice in Intellectual Disabilities, 8(1), 42-52. https ://doi. org/10.1111/j.1741-1130.2011.00288.x

Hahn, J. E., Fox, S., \& Janicki, M. (2015). Aging among older adults with intellectual and developmental disabilities: Setting national goals to address transitions in health, retirement, and late-life. Inclusion, $3(4), 250-259$.

Heslop, P., Blair, P. S., Fleming, P., Hoghton, M., Marriott, A., \& Russ, L. (2014). The Confidential Inquiry into premature deaths of people with intellectual disabilities in the UK: A population-based study. The Lancet, 383(9920), 889-895.

Janicki, M. P., Dalton, A. J., Henderson, C. M., \& Davidson, P. W. (1999). Mortality and morbidity among older adults with intellectual disability: Health services considerations. Disability Rehabilitation, 21(5-6), 284294. https ://doi.org/10.1080/09638 2899297710

Keele, L., Meert, K. L., Berg, R. A., Dalton, H., Newth, C. J. L., Harrison, R., ... Pollack, M. (2016). Limiting and withdrawing life support in the PICU: For whom are these options discussed?. Pediatric Critical Care Medice, 17(2), 110-120. https ://doi.org/10.1097/pcc.00000 00000000614

Kirkendall, A., Linton, K., \& Farris, S. (2017). Intellectual disabilities and decision making at end of life: A literature review. Journal of Applied Research in Intellectual Disabilities, 30(6), 982-994.

MAXQDA (2017). VERBI software (version 11). Retrived from https :// www.maxqda.com. Berlin, Germany McEvoy, J., Treacy, B., \& Quigley, J. (2017). A matter of life and death: Knowledge about the body and 
Voss, H., Vogel, A., Wagemans, A.M.A, Francke, A.L, Metsemakers, J.F.M., Courtens, A.M., Veer, A.J.E. What is important for advance care planning in the palliative phase of people with intellectual disabilities? A multiperspective interview study. Journal of applied research in intellectual disabilities (JARED) : 2020, 33(2), p. 160-171

concept of death in adults with intellectual disabilities. Journal of Intellectual Disability Research, 61(1), 8998. https ://doi.org/10.1111/jir.12347

McKenzie, N., Mirfin-Veitch, B., Conder, J., \& Brandford, S. (2017). "I'm still here": Exploring what matters to people with intellectual disability during advance care planning. Journal of Applied Research in Intellectual Disabilities, 30(60), 1089-1098. https ://doi.org/10.1111/jar.12355

McLaughlin, D., Barr, O., Mcllfatrick, S., \& McConkey, R. (2014). Developing a best practice model for partnership practice between specialist palliative care and intellectual disability services: A mixed methods study. Journal of Palliative Medicine, 28(10), 1213-1221. https ://doi.org/10.1177/02692 16314550373

Patja, K., livanainen, M., Vesala, H., Oksanen, H., \& Ruoppila, I. (2000). Life expectancy of people with intellectual disability: A 35-year follow- up study. Journal of Intellectual Disability Research, 44(5), 591- 599. https ://doi.org/10.1046/j.1365-2788.2000.00280.x

Rogne, L. (2013). Advance care planning: Communicating about matters of life and death. Ney York, NY: Springer Publishing Company.

Savage, T. A., Moro, T. T., Boyden, J. Y., Brown, A. A., \& Kavanaugh, K. (2015). Implementation challenges in end-of-life research with adults with intellectual and developmental disabilities. Journal of Applied Nursing Research, 28(2), 202-205. https ://doi.org/10.1016/j. apnr.2014.10.002

Singer, P. A., Martin, D. K., Lavery, J. V., Thiel, E. C., Kelner, M., \& Mendelssohn, D. C. (1998). Reconceptualizing advance care planning from the patient's perspective. Archives of Internal Medicine, 158(8), 879-884. https ://doi.org/10.1001/archi nte.158.8.879

Stancliffe, R. J., Wiese, M. Y., Read, S., Jeltes, G., \& Clayton, J. M. (2016). Knowing, planning for and fearing death: Do adults with intellectual disability and disability staff differ?. Research in Developmental Disabilities, 49-50, 47-59. https ://doi.org/10.1016/j.ridd.2015.11.016

Stancliffe, R. J., Wiese, M. Y., Read, S., Jeltes, G., \& Clayton, J. M. (2017). Assessing knowledge and attitudes about end of life: Evaluation of three instruments designed for adults with intellectual disability. Journal of Applied Research in Intellectual Disabilities, 30(6), 1076-1088. https ://doi.org/10.1111/jar.12358

Stein, G. L. (2008). Providing palliative care to people with intellectual disabilities: Services, staff knowledge, and challenges. Journal of Palliative Medicine, 11(9), 1241-1248. https ://doi.org/10.1089/ jpm.2008.0130

Tuffrey-Wijne, I. (2003). The palliative care needs of people with intellectual disabilities: A literature review. Palliative Medicine, 17(1), 55-62. https ://doi.org/10.1191/02692 16303 pm668oa

Tuffrey-Wijne, I. (2013). A new model for breaking bad news to people with intellectual disabilities. Palliative Medicine, 27(1), 5-12. https :// doi.org/10.1177/02692 16311433476

Tuffrey-Wijne, I., Bernal, J., \& Hollins, S. (2010). Disclosure and understanding of cancer diagnosis and prognosis for people with intellectual disabilities: Findings from an ethnographic study. European Journal of Oncology Nursing, 14(3), 224-230. https ://doi. org/10.1016/j.ejon.2010.01.021

Tuffrey-Wijne, I., \& McEnhill, L. (2008). Communication difficulties and intellectual disability in end-of-life care. International Journal of Palliative Nursing, 14(4), 189-194. https ://doi.org/10.12968/ ijpn.2008.14.4.29133 
Voss, H., Vogel, A., Wagemans, A.M.A, Francke, A.L, Metsemakers, J.F.M., Courtens, A.M., Veer, A.J.E. What is important for advance care planning in the palliative phase of people with intellectual disabilities? A multiperspective interview study. Journal of applied research in intellectual disabilities (JARED) : 2020, 33(2), p. 160-171

Tuffrey-Wijne, I., \& McLaughlin, D. (2015). Consensus norms for palliative care of people with intellectual disabilities in Europe, using Delphi methods: A white paper from the European association of palliative care. Palliative Medicine, 30(5), 446-455.

Tunney, R. J., \& Ziegler, F. V. (2015). Toward a psychology of surrogate decision making. Perspectives on Psychological Science, 10(6), 880-885. https ://doi.org/10.1177/17456 91615598508 van Schrojenstein Lantman-De Valk, H. M., Metsemakers, J. F.,

Haveman, M. J., \& Crebolder, H. F., (2000). Health problems in people with intellectual disability in general practice: A comparative study. Family Practice, 17(5), 405-407. https ://doi.org/10.1093/ fampr a/17.5.405

Voss, H., Vogel, A., Wagemans, A. M., Francke, A. L., Metsemakers, J. F., Courtens, A. M., \& de Veer, A. J. (2017). Advance care planning in palliative care for people with intellectual disabilities: A systematic review. Journal of Pain and Symptom Management, 54(6), 938-960.e1. https ://doi.org/10.1016/j.jpain symman.2017.04.016

Vrijmoeth, C., Barten, P., Assendelft, W. J. J., Christians, M. G. M., Festen, D. A. M., Tonino, M., ... Groot, M. (2016). Physicians' identification of the need for palliative care in people with intellectual disabilities. Research in Developmental Disabilities, 59, 55-64. https ://doi. org/10.1016/j.ridd.2016.07.008

Vrijmoeth, C., Christians, M. G., Festen, D. A., Groot, M., Tonino, M., \& Echteld, M. A. (2016). Physicians' recognition of death in the foreseeable future in patients with intellectual disabilities. Journal of Intellectual Disability Research, 60(3), 207-217. https ://doi. org/10.1111/jir.12240

Wagemans, A., van Schrojenstein Lantman-de Valk, H., Proot, I., Metsemakers, J., Tuffrey-Wijne, I., \& Curfs, L. (2012). The factors affecting end-of-life decision-making by physicians of patients with intellectual disabilities in the Netherlands: A qualitative study. Journal of Intellectual Disability Research, 57(4), 380389. https ://doi. org/10.1111/j.1365-2788.2012.01550.x

Wagemans, A. M. A., Van Schrojenstein Lantman-de Valk, H. M. J., Proot, I. M., Metsemakers, J., Tuffrey-Wijne, I., \& Curfs, L. M. G. (2013). End-of-life decisions for people with intellectual disabilities, an interview study with patient representatives. Palliative Medicine, 27(8), 765-771. https ://doi.org/10.1177/02692 16312 468932

Wagemans, A., van Schrojenstein Lantman-de-Valk, H., Tuffrey-Wijne, l., Widdershoven, G., \& Curfs, L. (2010). End-of-life decisions: An important theme in the care for people with intellectual disabilities. Journal of Intellectual Disability Research, 54(6), 516-524. https ://doi. org/10.1111/j.1365-2788.2010.01276.x

Watson, J. (2016). Assumptions of decision-making capacity: The role supporter attitudes play in the realisation of Article 12 for people with severe or profound intellectual disability. Laws, 5(1), 6.

Watson, J., Wilson, E., \& Hagiliassis, N. (2017). Supporting end of life decision making: Case studies of relational closeness in supported decision making for people with severe or profound intellectual disability. Journal of Applied Research in Intellectual Disabilities, 30(6), 1022-1034. https ://doi.org/10.1111/jar.12393

WHO (2019). Definition of palliative care. Retrieved from https ://www

Wiese, M., Dew, A., Stancliffe, R. J., Howarth, G., \& Balandin, S. (2013). 'If and when?': The beliefs and experiences of community living staff in supporting older people with intellectual disability to know about dying. Journal of Intellectual Disability Research, 57(10), 980-992. https ://doi.org/10.1111/j.13652788.2012.01593.x 
Voss, H., Vogel, A., Wagemans, A.M.A, Francke, A.L, Metsemakers, J.F.M., Courtens, A.M., Veer, A.J.E. What is important for advance care planning in the palliative phase of people with intellectual disabilities? A multiperspective interview study. Journal of applied research in intellectual disabilities (JARED) : 2020, 33(2), p. 160-171

Wiese, M., Stancliffe, R. J., Dew, A., Balandin, S., \& Howarth, G. (2014). What is talked about? Community living staff experiences of talking with older people with intellectual disability about dying and death. Journal of Intellectual Disability Research, 58(7), 679-690. https ://doi. org/10.1111/jir.12065

How to cite this article: Voss $\mathrm{H}$, Vogel $\mathrm{A}$, Wagemans AMA, et al. What is important for advance care planning in the palliative phase of people with intellectual disabilities? A multi-perspective interview study. J Appl Res Intellect Disabil. 2019;00:1-12. https ://doi.org/10.1111/jar.12653 
Voss, H., Vogel, A., Wagemans, A.M.A, Francke, A.L, Metsemakers, J.F.M., Courtens, A.M., Veer, A.J.E. What is important for advance care planning in the palliative phase of people with intellectual disabilities? A multiperspective interview study. Journal of applied research in intellectual disabilities (JARED) : 2020, 33(2), p. 160-171

\section{Tables and figures}

Table 1: Background characteristics of participants

\begin{tabular}{|c|c|c|c|}
\hline & Interview & Participants & \\
\hline \multirow{6}{*}{$\begin{array}{l}\text { People with intellectual } \\
\text { disability (ID) }\end{array}$} & & & Sex; age; degree of intellectual disabilities \\
\hline & 1 & (1) $\mathrm{J}$ & Male; 71 y old; moderate intellectual disabilities \\
\hline & 2 & (2) L. & Female; 83 y old; moderate intellectual disabilities \\
\hline & 3 & (3) T. & Female; 83 y old; moderate intellectual disabilities \\
\hline & 4 & (4) $\mathrm{N}$. & Female; 81 y old; moderate intellectual disabilities \\
\hline & 5 & (5) R. & Male; 40 y old; moderate intellectual disabilities \\
\hline \multirow[t]{6}{*}{ Relatives } & & & $\begin{array}{l}\text { Initial of their relative with intellectual disabilities: sex; age; } \\
\text { illness or cause of death; degree of intellectual disabilities }\end{array}$ \\
\hline & 6 & $\begin{array}{l}\text { (1) Mother } \\
\text { (2) Father }\end{array}$ & P.: male; 47 y old; malignancy; severe intellectual disabilities \\
\hline & 7 & (3) Sister & $\begin{array}{l}\text { T.: female; } 62 \text { y old at death; died in } 2017 \text { from frailty in old } \\
\text { age; moderate intellectual disabilities }\end{array}$ \\
\hline & 8 & (4) Sister & $\begin{array}{l}\text { G.: female; } 61 \text { y old; dementia; moderate intellectual } \\
\text { disabilities }\end{array}$ \\
\hline & 9 & $\begin{array}{l}\text { (5) Mother } \\
\text { (6) Father }\end{array}$ & $\begin{array}{l}\text { G.: male; } 20 \text { y old; co-morbid somatic illness; profound intel- } \\
\text { lectual disabilities }\end{array}$ \\
\hline & 10 & (7) Mother & $\begin{array}{l}\text { J.: male; } 14 \text { y old; co-morbid somatic illness; severe intellectual } \\
\text { disabilities }\end{array}$ \\
\hline \multirow[t]{9}{*}{ Professionals } & & & Work experience as a professional in intellectual disability care \\
\hline & 11 & (1) Intellectual disability physician & $30 y$ \\
\hline & 12 & (2) Nurse specialized in palliative care & $16 y$ \\
\hline & & (3) Nurse specialized in palliative care & $41 \mathrm{y}$ \\
\hline & 13 & $\begin{array}{l}\text { (4) Nurse specialized in care for peo- } \\
\text { ple with intellectual disabilities }\end{array}$ & $30 y$ \\
\hline & 14 & (5) Behavioural specialist & $8 y$ \\
\hline & & (6) Behavioural specialist & $30 y$ \\
\hline & 15 & (7) Nurse & $22 y$ \\
\hline & & (8) Social worker & $10 \mathrm{y}$ \\
\hline
\end{tabular}

Box 1: Topic list for in-depth interviews ( $n=15)$

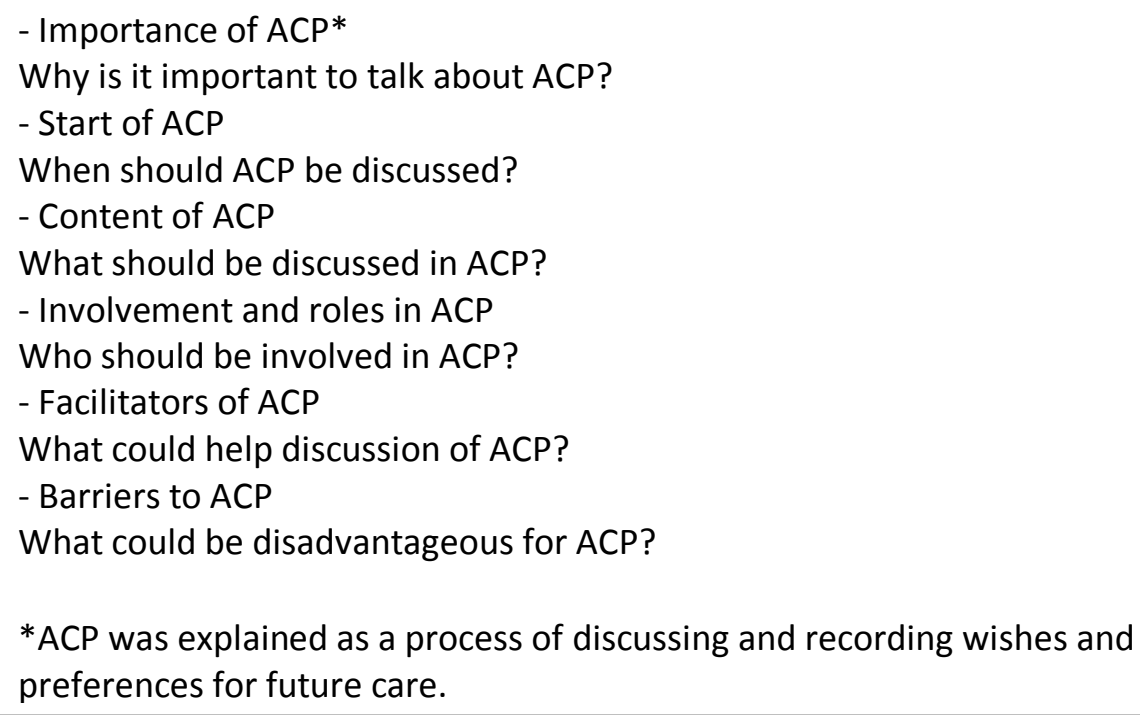


Voss, H., Vogel, A., Wagemans, A.M.A, Francke, A.L, Metsemakers, J.F.M., Courtens, A.M., Veer, A.J.E. What is important for advance care planning in the palliative phase of people with intellectual disabilities? A multiperspective interview study. Journal of applied research in intellectual disabilities (JARED) : 2020, 33(2), p. 160-171

Figure 1: Representation of themes indicating what people with intellectual disabilities, their relatives and professionals perceived as important for ACP in relation to the research question: "What should the ACP process look like?"

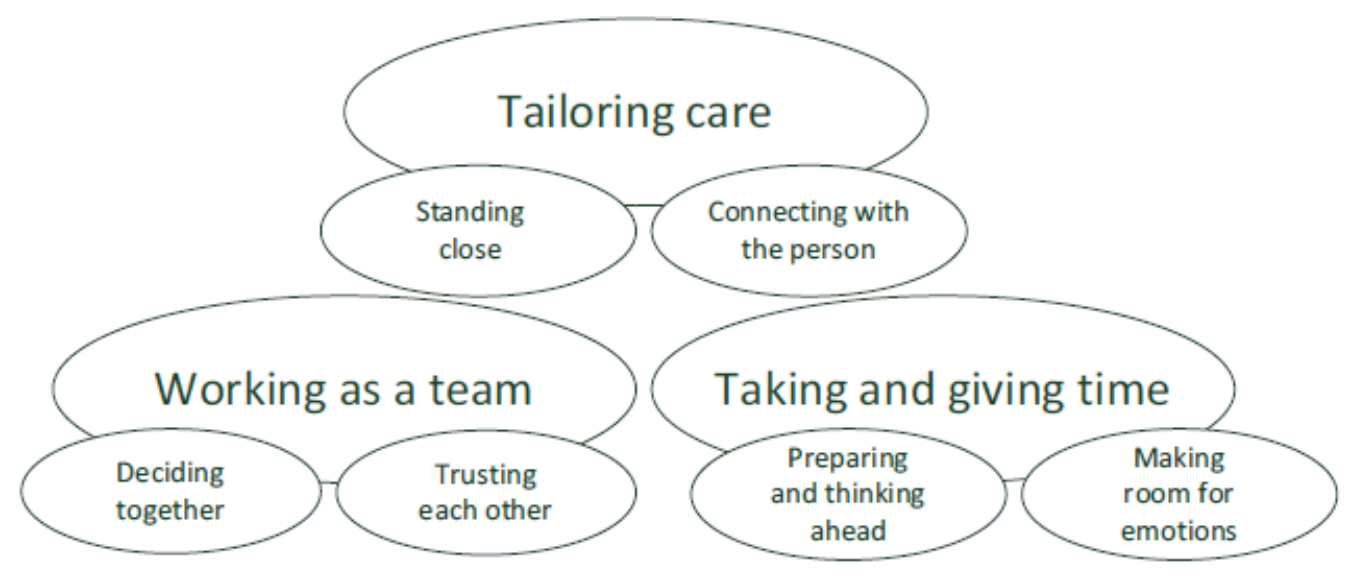

Figure 2: Description of the roles depicted for the research question: "What roles should people with intellectual disabilities, their relatives and professionals have in ACP?"

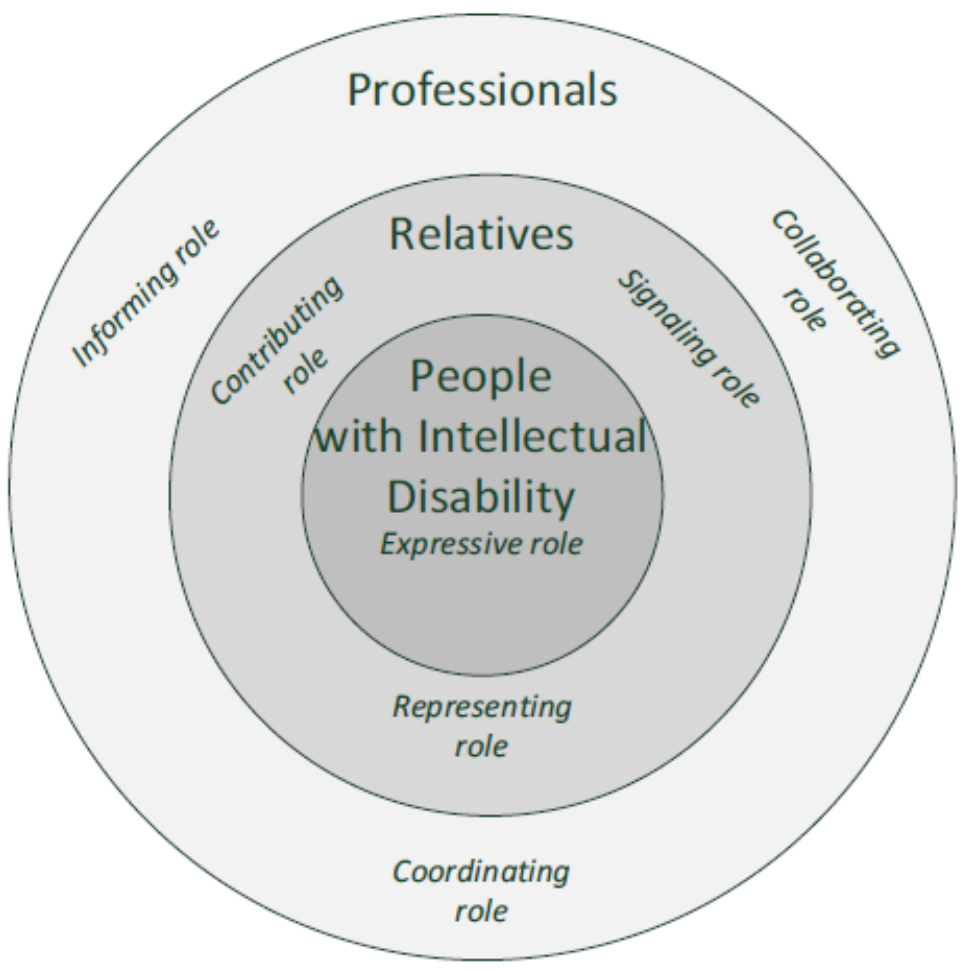

